\title{
Structure and Properties of New Antifriction Composites Based on Tool Steel Grinding Waste
}

\author{
Tetiana Roik ${ }^{1}\left(\mathbb{D}\right.$, Ahmad Rashedi ${ }^{2,3, *}$, Taslima Khanam ${ }^{2, *}$, Abhay Chaubey ${ }^{4} \mathbb{D}$, Gurusami Balaganesan ${ }^{5}$ and \\ Sadaqat Ali 6
}

1 Publishing and Printing Institute, National Technical University of Ukraine “Igor Sikorsky Kyiv Polytechnic Institute", 37 Peremogy Avenue, 03057 Kyiv, Ukraine; roik2011@gmail.com

2 College of Engineering, IT \& Environment, Charles Darwin University, Ellengowan Drive, Casuarina, NT 0810, Australia

3 A*Star Sustainability, Allwright Street, Wanguri, NT 0810, Australia

4 Department of Civil Engineering, SRM University, Delhi-NCR, Sonepat 131029, India; abhaychaubey26@gmail.com

5 Department of Mechanical Engineering, Indian Institute of Technology Jammu, Jammu 181221, India; gbganesh@iitm.ac.in

6 Department of Mechanical Engineering, National University of Sciences and Technology, Islamabad 44000, Pakistan; sadaqat.ali@smme.nust.edu.pk

* Correspondence: mabrur.rashedi@cdu.edu.au (A.R.); taslima.khanam@cdu.edu.au (T.K.)

\section{check for} updates

Citation: Roik, T.; Rashedi, A.; Khanam, T.; Chaubey, A.;

Balaganesan, G.; Ali, S. Structure and Properties of New Antifriction Composites Based on Tool Steel Grinding Waste. Sustainability 2021, 13, 8823. https://doi.org/10.3390/ su13168823

Academic Editors:

Yoshiki Shimomura and

Shigeru Hosono

Received: 6 July 2021

Accepted: 4 August 2021

Published: 6 August 2021

Publisher's Note: MDPI stays neutral with regard to jurisdictional claims in published maps and institutional affiliations.

Copyright: (c) 2021 by the authors. Licensee MDPI, Basel, Switzerland. This article is an open access article distributed under the terms and conditions of the Creative Commons Attribution (CC BY) license (https:/ / creativecommons.org/licenses/by/ $4.0 /)$.

\begin{abstract}
This article investigates the impact of manufacturing technology on the structure, mechanical, and tribological properties of new antifriction composite materials based on R6M5 high-speed tool steel grinding waste. The characteristics of the new composite's structure formation and its impact on properties after use of the established technological modes, including grinding waste regeneration, were illustrated. It was demonstrated that such technology is capable of ensuring microheterogeneous structure. The material's structure consists of the metal matrix based on R6M5 high-speed tool steel waste and uniformly distributed $\mathrm{CaF}_{2}$ solid lubricant in the steel matrix. As compared to known iron-based composites, this structure promotes a high degree of mechanical and tribological properties. During tribological tests, anti-seize thin films of 15-20 $\mu \mathrm{m}$ are formed on the contacting surfaces. These constantly renewable films contribute to the high antifriction properties of the composite under the studied friction conditions and provide a self-lubricating effect. Such films fully cover both the material's surface and the counterface. The formation of antifriction films results in the self-lubrication mode. The findings of the study open up the possibility of predicting the friction behavior of a composite at high temperatures by selecting the initial metal grinding waste to ensure the appropriate level of properties. The extensive use of various alloy steel-based industrial grinding waste in the re-production cycle would significantly contribute to resolving the global environmental problem of protecting the environment from pollution.
\end{abstract}

Keywords: grinding waste; composite material; technology; structure; properties; antifriction load; temperature

\section{Introduction}

Most modern machines and mechanisms have moving friction parts that work in different conditions. Currently, a large number of antifriction (bearing) cast materials based on ferrous and non-ferrous metals and composite materials obtained by powder metallurgy methods have been developed [1-3]. However, in most cases, parts working in friction units, in particular, plain bearings, fail much earlier than other parts of machines. This necessitates the completion of work on equipment repair and the production of a large number of replacement parts. This leads to high material and financial costs. A lot of cast and composite antifriction materials, such as plain bearings, have been developed and used today. These are materials based on ferrous and non-ferrous metals, polymer materials, 
etc. This variety of antifriction materials is due to the conditions of their operation during friction. Such friction conditions vary widely from light conditions to severe operating conditions at high temperatures, loads, in an aggressive environment, etc. Therefore, antifriction materials for heavy working conditions take a special place among other materials working in friction units. Very high demands are placed on such materials. These materials must retain high mechanical and tribological properties at high temperatures under the simultaneous action of a load and have sufficient heat resistance. Iron-based materials are commonly used for extreme operating conditions of bearing materials in the air at temperatures ranging from 450 to $500{ }^{\circ} \mathrm{C}$ and increased loads (up to $7.0 \mathrm{MPa}$ ). Other non-ferrous metals, such as copper-based alloys, demonstrate either unsatisfactory tribological properties or are inoperative under such operating conditions. Moreover, such materials are expensive [1-3].

Iron-based materials no longer meet the increasing demands of modern equipment. Cast materials have inadequate performance properties (high friction coefficient and wear) or are completely inoperative in a variety of cases. Furthermore, cast materials cannot contain various types of substances in their composition. Current powder materials are free of such drawbacks, but they are expensive, owing primarily to the high cost of raw materials (powders) $[1,3,4]$.

At the same time, there are numerous potential sources of low-cost useful raw materials throughout the world. This is the grinding waste from machine-building, metallurgical, and instrument-making processing of non-ferrous and ferrous metals and alloys. They are disposed of in large amounts in dumps due to abrasive contamination from grinding wheels and are not reused in the manufacturing cycle. Pollution of grinding waste with abrasive particles from grinding wheels (corundum particles) prevents their reuse.

Grinding waste of high-speed tool steels T1, M2 (ASTM International A600 standard), tool steel 1.3343 (DIN EN ISO 4957), tool steel SKH51 (JIS G4403 standard), and others are such contaminated waste by abrasives from grinding wheels that makes their reuse impossible. Tens of tonnes of metal grinding waste are produced every day by machine-manufacturing, instrument-making, and other businesses. This industrial waste is extremely polluting to the environment. At the same time, this steel grinding waste produces a high concentration of useful alloying elements such as $\mathrm{W}, \mathrm{Mo}, \mathrm{V}, \mathrm{Co}, \mathrm{Al}, \mathrm{Ti}, \mathrm{Cr}$, $\mathrm{Nb}$, and so on. After proper processing, such useful waste can be efficiently used in the subsequent production cycle.

The authors initiated research work on the regeneration and subsequent use of some types of ferrous and non-ferrous metal-based grinding waste to obtain new bearings, and promising results were obtained [5-7]. Such studies are one of the first steps in using grinding metal waste to make new antifriction composites. Besides, materials scientists [8,9] around the world have not focused on research devoted specifically to the use of metal grinding waste in a recycled production cycle, as research journal databases such as Scopus and the Web of Science affirm. As a rule, world scientists' research is devoted to the problems of metal shavings reuse, recycling of metal containers, cans, etc.

Thus, this study represents an innovative topic in the relevant field of knowledge, which was started by the authors of [5-7]. The complexities arise in grinding waste regeneration problems, development of the manufacturing processes, features of the anisotropic composites structure and their properties, the behavior of materials in the process of friction at high temperatures, loads, etc. Unfortunately, none of these issues has been studied well. Thus, a lot of scientific and practical issues remain unresolved in this area. Therefore, studies devoted to solving the above-mentioned problems are crucially important and novel.

As a result, developing new composite antifriction materials, for severe operating conditions and with high-performance properties, out of inexpensive and useful raw materials is critical. This is particularly true when it comes to locating usable raw materials, developing resource-saving technology, and protecting the environment from pollution. This is a critical issue from both a theoretical and a practical standpoint. 
The aim of this research is to investigate the impact of manufacturing technology on the structure and properties formation of new composite antifriction materials based on R6M5 high-speed tool steel grinding waste (analog of high-speed steel M2, AISI standard) with $\mathrm{CaF}_{2}$ solid lubricant additives.

\section{Methodology}

\subsection{Preparatory Procedures}

The subject of study is a new antifriction composite material based on R6M5 highspeed tool steel grinding waste with $\mathrm{CaF}_{2}$ solid lubricant (Table 1) [10,11].

Table 1. Chemical composition of the materials based on R6M5 high-speed tool steel grinding waste.

\begin{tabular}{cccccccccccccc}
\hline \multicolumn{10}{c}{ Components, wt. \% } \\
\hline $\mathbf{C}$ & $\mathbf{W}$ & $\mathbf{C r}$ & $\mathbf{M o}$ & $\mathbf{S i}$ & $\mathbf{M n}$ & $\mathbf{V}$ & $\mathbf{P r}$ & $\mathbf{C a F}$ \\
\hline $0.82-0.90$ & $5.5-6.5$ & $3.8-4.4$ & $4.8-5.3$ & $0.3-0.5$ & $0.3-0.5$ & $1.7-2.1$ & $0.02-0.025$ & $0.02-0.03$ & basis & $4.0-6.0$ \\
\hline
\end{tabular}

R6M5 steel is the closest analog of M2 high-speed tool steel, ASTM standard, components, wt.\%: C-0.78-0.88; W-5.5-6.75; Cr-3.75-4.50; Mo-4.5-5.5; Si-0.2-0.45; $\mathrm{Mn}-0.15-0.40 ; \mathrm{V}-1.75-2.20 ; \mathrm{S}-0.03 ; \mathrm{P}-0.03 ; \mathrm{Fe}-$ basis. The R6M5 steel grinding waste is formed during the grinding process of cutters, drills, and similar parts. This waste is polluted with abrasive particles from grinding wheels, such as corundum particles. Therefore, such waste is usually not used in the subsequent production cycle [6,7]. However, this steel contains valuable alloying elements (Table 1).

In addition, the specified steel belongs to the class of heat-resistant steels [8-10]. It retains sufficiently high strength properties up to temperatures of $500-600{ }^{\circ} \mathrm{C}$ and has a high heat resistance, which is primarily due to the presence of alloying elements (Table 1). Therefore, R6M5 high-speed tool steel is attractive for use as the basis for high-temperature antifriction (bearing) composite material.

To clean the grinding waste from abrasive particles, the method of magnetic separation was used, which allows separating the metal component from the non-metallic abrasive one $[6,7]$. The abrasive remains are $1-2 \%$ after the metal waste powders cleaning.

Particles of R6M5 steel powders have the form of microchips with sizes of $0.05-0.15 \mathrm{~mm}$, which can be seen from Figure 1.

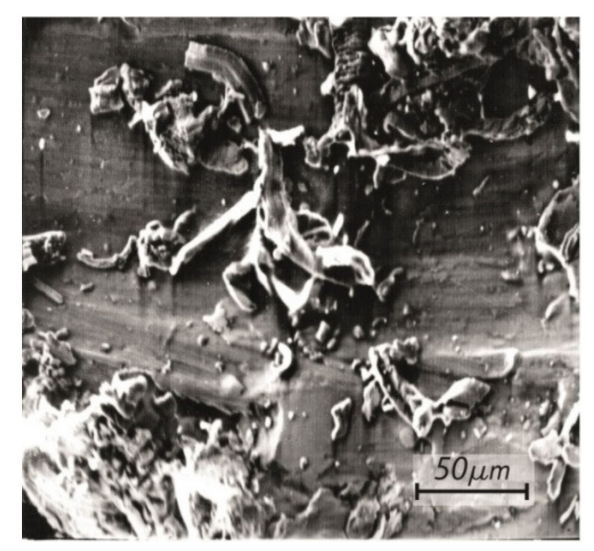

Figure 1. Particles of R6M5 steel powders after regeneration.

After cleaning, the metal powders were subjected to regenerative annealing at temperatures of $850-1000{ }^{\circ} \mathrm{C}$ in a hydrogen atmosphere to remove excess oxygen, which is present in the form of iron and alloying elements oxides. The oxygen content in the R6M5 steel waste powders is $0.8-1.0 \%$ before annealing, which negatively affects the structure and mechanical properties of materials [7]. In addition, an increased amount of oxygen requires an increase in pressing loads to achieve the proper density of the briquettes and also increases 
the press-forms wear. The regenerative annealing reduces the total oxygen concentration in powders from $1.0 \%$ in initial content to $0.4 \%$ after annealing. This contributes to the homogeneous microstructure formation.

After the reduction annealing, the conglomerates were ground on a crushing machine, and the particle size distribution was determined. After crushing the conglomerate, the powders were sieved into fractions. For the experiments, powders of R6M5 steel with dimensions of 160-200 $\mu \mathrm{m}$ were used since these dispersed powders provide the best formability.

For severe operating conditions of a friction pair, when the influence of high temperatures (up to $500{ }^{\circ} \mathrm{C}$ ) is present among other loading factors, and no liquid lubricant is efficient, it is especially important to protect the friction surfaces from increased wear and seizure. For this, substances that act as a solid lubricant are used.

The use of a certain substance is determined by the material of the contact surfaces, friction conditions, mechanical and chemical properties of substances, their thermal stability in relation to the environment, and interaction with the materials of the friction pair. Currently, more than 100 substances were investigated and described $[6,7,12-16]$, and they are used as solid lubricants.

The number of recommended anti-seize lubricants is explained by the variety of operating conditions for antifriction parts. Therefore, certain antifriction additives are used when they give the greatest effect precisely for certain specific conditions. Meanwhile, the experience of work [12-16] and the analysis of literary sources on this issue convincingly showed the promise of using calcium fluoride as a solid lubricant specifically for extreme operating conditions (high temperatures, loads, aggressive environment-air).

Considering the rather high thermal and chemical stability of $\mathrm{CaF}_{2}[16,17]$, it can be assumed that bearing (antifriction) materials with the addition of calcium fluoride will meet the requirements of friction and wear in severe operating conditions. The amount of $\mathrm{CaF}_{2}$ was chosen in the range of $4-6 \mathrm{wt} . \%$ for the following reasons [6,7]: with a content of less than $4 \% \mathrm{CaF}_{2}$, the functions of a solid lubricant are not fully fulfilled, and with a content of more than $6-8 \%$, the strength and plasticity of the material are very reduced.

\subsection{Preparation of Powder Charge, Compaction, and Sintering}

Thus, after carrying out preparatory operations for cleaning grinding waste steel, preparing powders of solid lubricant $\mathrm{CaF}_{2}$ (drying for $1 \mathrm{~h}$ at $120^{\circ} \mathrm{C}$ and sifting fractions to $125 \mu \mathrm{m})$, the initial charge was prepared.

The components of the charge ( $\mathrm{R} 6 \mathrm{M} 5$ steel waste and $\mathrm{CaF}_{2}$ powders) were mixed in a can mixer for $4 \mathrm{~h}$ and subjected to pressing at a pressure of 700-900 MPa. As a result of pressing, briquettes were obtained with a porosity of $20-22 \%$. Pressing at pressures less than 700 MPa results in a high porosity of $34-36 \%$, and this leads to an almost complete loss of the briquettes integrity. At pressures of more than $900 \mathrm{MPa}$, stratification of briquettes occurred, which was associated with the difference in the density of the charge's initial components.

After pressing, the samples of materials were sintered in a muffle furnace in dried hydrogen (dew point is $-40^{\circ} \mathrm{C}$ ). Studies of the sintering temperature influence for composite's properties were performed in the temperature range $800-1200^{\circ} \mathrm{C}$. Changes in some properties of the investigated material depending on the sintering temperature are shown in Figure 2.

As it can be seen from Figure 2, the evolution of the porous and grain structure of a powder material during sintering significantly affects the properties of materials, and this is the more noticeable and influential, the higher the sintering temperature.

It can be seen from Figure 2 that the volume shrinkage, hardness, and impact toughness of the material increase with an increase in the sintering temperature, but the rate of increase in these characteristics is not the same. This is due to the phenomenon of structural sensitivity of various properties. Thus, according to [18-21], the plastic properties of materials (also magnetic) have the highest structural sensitivity, followed by strength 
characteristics such as hardness, strength, elastic modulus, and, finally, magnetic induction and electrical conductivity.

A significant increase in volume shrinkage and mechanical properties (HB and $\mathrm{KC}$ ) begins with a sintering temperature of $900{ }^{\circ} \mathrm{C}$. At lower sintering temperatures $800-900{ }^{\circ} \mathrm{C}$, the volume shrinkage of the material is much lower (Figure 2). Here, shrinkage is largely due to interparticle displacement, and the interparticle contacts are not yet mature enough, and they contain so-called suture porosity. Therefore, the corresponding properties are too small, namely hardness and especially the ductility of samples sintered at $800-900{ }^{\circ} \mathrm{C}$.

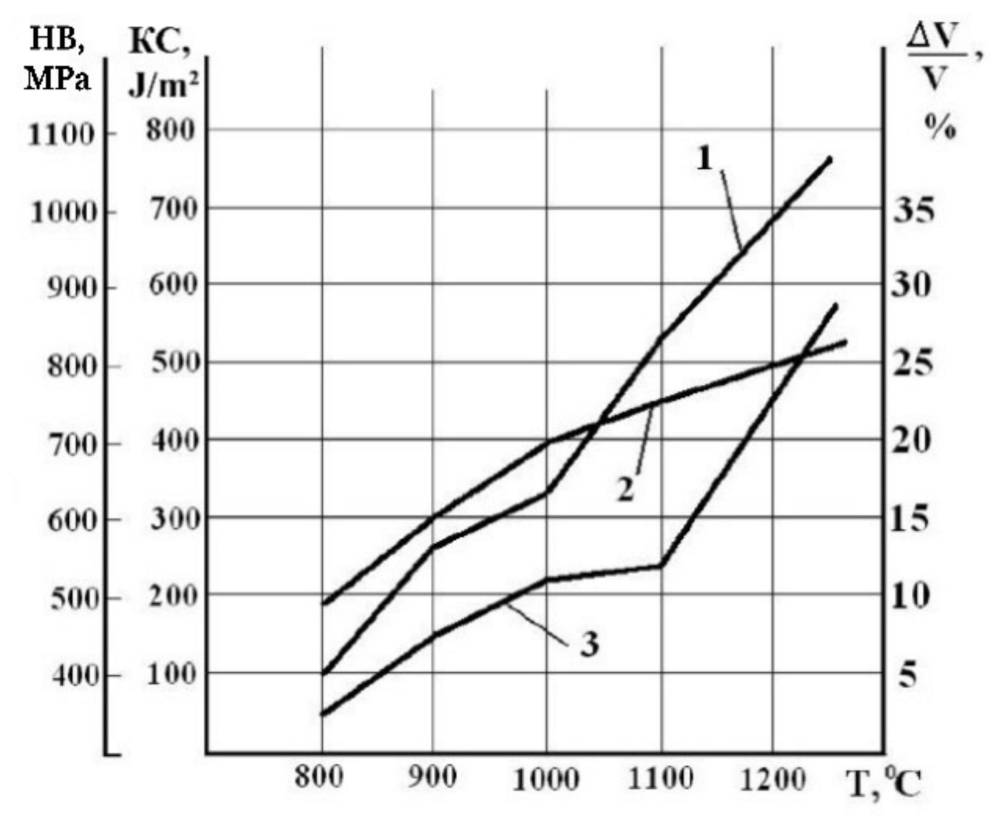

Figure 2. Dependence of the composite $\mathrm{R} 6 \mathrm{M} 5+5 \% \mathrm{CaF}_{2}$ properties on the sintering temperature: 1-impact toughness, 2-hardness, 3-volume shrinkage.

An essential increase in volumetric shrinkage at $1200{ }^{\circ} \mathrm{C}$ for the studied material, as well as an increase in mechanical properties, indirectly indicates the diffusion processes activation and the formation of interparticle contacts. This also indicates an increase in the alloying degree of solid solutions and phases formed during sintering.

Sintering at temperatures above $1200{ }^{\circ} \mathrm{C}$ is impractical due to the beginning of calcium fluoride dissociation, and complete decomposition of $\mathrm{CaF}_{2}$ occurs at $1314{ }^{\circ} \mathrm{C}[3,17]$.

Thus, it was found the sintering should be carried out at temperatures of $1150-1200{ }^{\circ} \mathrm{C}$, which provide the maximum density. After sintering, the porosity was $11-13 \%$, and rather high mechanical properties were formed (Figure 2).

\subsection{Examination Techniques}

The structure was studied using optical and raster electron microscopes; calcium fluoride in the matrix was identified using scanning electron microscopy (SEM). The mechanical properties of the samples were determined by standard methods. Tribological tests were performed on a VMT- 1 friction testing machine (the temperature of up to $500{ }^{\circ} \mathrm{C}$, the sliding speed of $\mathrm{V}=1.0 \mathrm{~m} / \mathrm{sec}$, and the load of 1.5-7.0 MPa), the counterface was made of the R18 cast tool steel (analog of high-speed steel T1, AISI standard, hardness 54-57 HRC). The counterface material R18 steel corresponded to the material of the real shafts in the high-temperature friction units. The R18 steel has the following chemical composition, wt. \%: $0.73-0.83$ of carbon, to 0.5 of silicon, to 0.5 of manganese, $3.8-4.4$ of chromium, $17.0-18.0$ of tungsten, to 1.0 of molybdenum, 1.0-1.4 of vanadium, to 0.03 of sulfur, to 0.03 of phosphorus, and iron as the base. 


\section{Results and Discussion}

A complex heterogeneous structure was formed as a result of the developed technological modes of manufacturing. The microstructure consists of a metal matrix based on R6M5 steel grinding waste and particles of $\mathrm{CaF}_{2}$ solid lubricant (Figure 3).



(a)



(b)

Figure 3. Microstructure of the composite $\mathrm{R} 6 \mathrm{M} 5+5 \% \mathrm{CaF}_{2}$. (a) not etched thin section; (b) etched thin section.

The metal matrix of the $\mathrm{R} 6 \mathrm{M} 5+5 \% \mathrm{CaF}_{2}$ material has a pearlite-carbide structure, consisting of the $\alpha$-solid solution and alloying elements carbides (Figure 3b). Particles of $\mathrm{CaF}_{2}$ solid lubricant are uniformly distributed in the metal matrix of the composite (Figure 3a).

The specified structure is the most favorable for the optimal combination of high mechanical and tribological properties from the point of view of the general regularity for antifriction purposes materials. The properties of the examined composite are presented in Tables 2 and 3.

Table 2. Mechanical properties of composite based on R6M5 steel waste powders.

\begin{tabular}{cccc}
\hline Composition, wt. \% & $\begin{array}{c}\text { Bending Strength, } \\
\boldsymbol{\sigma}_{\mathbf{s}}, \mathbf{M P a}\end{array}$ & $\begin{array}{c}\text { Impact Toughness, } \\
\mathbf{K C}, \mathbf{J} / \mathbf{m}^{2}\end{array}$ & Hardness, HB, MPa \\
\hline R6M5 + 5CaF 2 & $320-360$ & $690-710$ & $800-820$ \\
\hline Fe3CMo (ZhC3M) [3] & $250-270$ & $550-580$ & $600-620$ \\
\hline
\end{tabular}

Table 3. Tribological properties of composite based on R6M5 steel waste *.

\begin{tabular}{cccc}
\hline Composition, wt. $\%$ & $\begin{array}{c}\text { Bending Strength, } \boldsymbol{\sigma}_{\mathbf{s}}, \\
\mathbf{M P a}\end{array}$ & $\begin{array}{c}\text { Impact Toughness, } \\
\mathbf{K C}, \mathbf{~} / \mathbf{m}^{\mathbf{2}}\end{array}$ & Hardness, HB, MPa \\
\hline R6M5 $+5 \mathrm{CaF}_{2}$ & $320-360$ & $690-710$ & $800-820$ \\
\hline Fe3CMo $(\mathrm{ZhC} 3 \mathrm{M})[3]$ & $250-270$ & $550-580$ & $600-620$ \\
\hline *-friction coefficient and wear rate at $\mathrm{t}=450{ }^{\circ} \mathrm{C}$. &
\end{tabular}

Analysis of Table 2 shows the material based on R6M5 steel waste powders has much higher mechanical properties compared to the known antifriction composite such as irongraphite alloyed with $13 \%$ Mo [3]. This is due to the high degree of the new composite alloying, which provides the formation of the above-described homogeneous structure.

The series of tribological tests were carried out at various loads to determine the rational load ranges for the new composites. During the experiments, 10 samples were tested at each load.

The antifriction properties of the examined composite based on R6M5 steel waste powders are presented in Table 3 compared to the known one. 
As shown in Table 3, the structure of materials based on R6M5 steel waste provides a high level of tribological properties that remain in a wide range of loads on a friction pair at an external heating temperature of $500{ }^{\circ} \mathrm{C}$ in an aggressive environment (air). Tribological tests at loads of 1.5-7.0 $\mathrm{MPa}$ allowed determining the rational operating range of the composite based on R6M5 steel waste with the $\mathrm{CaF}_{2}$ solid lubricant additions.

By analyzing the data in Tables 2 and 3, it becomes obvious the new composite has higher both mechanical and antifriction properties in comparison with the currently used material for similar conditions [3]. Waste-based composite is also able to operate at higher temperatures and withstand much higher maximum loads. In addition, the new composite contains powders of a more efficient solid lubricant such as $\mathrm{CaF}_{2}$ for high-temperature operation, as opposed to graphite in the known composite [3] applied in similar conditions.

During the friction process, anti-seize thin films of 15-20 $\mu \mathrm{m}$ are formed on the contacting surfaces, which are carriers of high antifriction properties. Such films are the third participant in the friction process. The self-lubrication mode is realized due to the formation of such antifriction films.

These films completely cover both the surface of the material and the counterface. An image of the friction surfaces is shown in Figure 4.

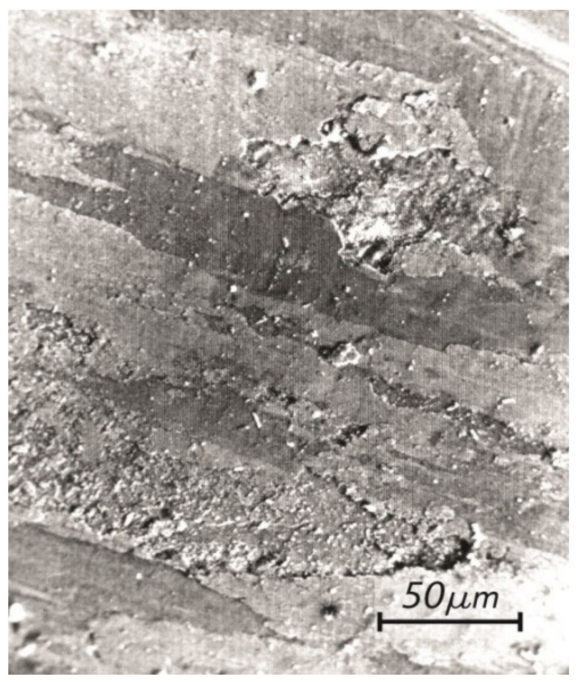

(a)

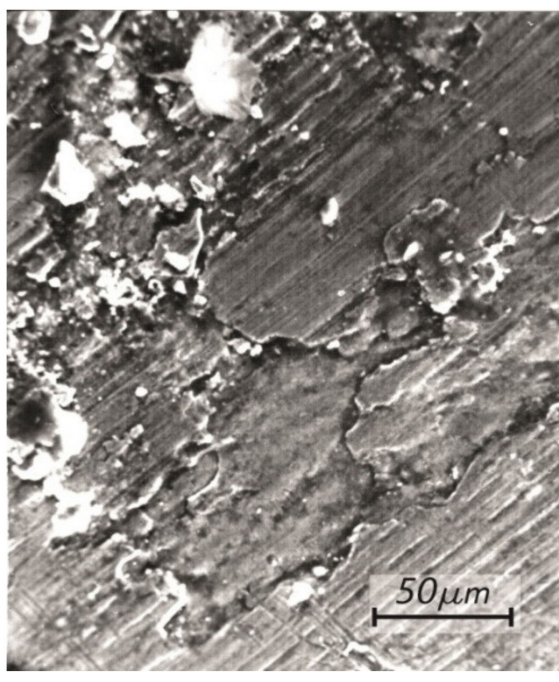

(b)

Figure 4. Friction surfaces. (a) composite R6M5 $+5 \% \mathrm{CaF}_{2} ;$ (b) counterface of R18 high-speed tool steel.

Antifriction films are constantly formed and wear out at the same time. Under researched friction modes, there is a balance between the wear rate of these films and the rate of new films areas formation. Such antifriction films cover the contact surfaces and protect the friction pair from intense wear.

\section{Conclusions}

The research results showed the possibility of the alloyed grinding waste effective for the manufacture of new composites with high functional properties. The experimental results showed the selected manufacturing modes provide the formation of a complex heterophase structure of composites based on R6M5 steel high-alloyed waste powders. Such structure ensures a high level of functional properties of new antifriction composites manufactured from regenerated grinding waste.

Comprehensive studies demonstrated the features of the formation of the composite's structure using R6M5 steel waste powders as a basis, taking into account the nature of the components present. This allows predicting the nature of the strengthening and material's antifriction behavior, and hence functional properties. 
The approach chosen in the research opens up wide possibilities for controlling the composites' structure and properties by choosing the initial waste powders introduced into the starting powder mixture to form the strong metal matrix and adding the solid lubricant by the necessary amount $[22,23]$.

As studies have shown, the new material's rational operating range is followed: the external working loads on contact pair of 1.5-7.0 MPa at a temperature of $500{ }^{\circ} \mathrm{C}$ in air and a sliding speed of $1 \mathrm{~m} / \mathrm{sec}$, when the composite demonstrates the highest properties, which ensure the friction pair stable operation.

Further research will be aimed at determining the elemental and phase composition of the formed antifriction films, which provide high functional properties in severe operation modes. It is also planned to carry out experimental studies to expand the range of using the valuable grinding waste of ferrous and non-ferrous metals for quality antifriction part manufacturing.

The results of comprehensive research indicate the feasibility and great possibilities of using a wide range of alloyed steel grinding waste in the re-production cycle for the manufacture of high-quality parts for different operating conditions.

The widespread use of valuable industrial grinding waste in the re-production cycle will make a great contribution to solving the global environmental problem of protecting the environment from pollution. The reuse of hundreds of tonnes of metal waste will significantly reduce their disposal to dumps, which will contribute to metal reuse, recycling, and circular economy strategies. The primary metal manufacturing processes accompany significant GHG emissions and other environmental impacts, and these belong to energyintensive processes $[24,25]$. Through enhanced recycling or reuse, we can reduce these environmental impacts and energy use, thus ultimately contributing to global sustainability.

Author Contributions: Conceptualization, T.R. and A.R.; methodology, T.R. and A.R.; software, T.R.; validation, T.R., A.R., T.K., A.C. and S.A.; investigation, T.R. and A.R.; resources, T.R.; data curation, T.R.; writing-original draft preparation, T.R. and A.R.; writing-review and editing, T.R., A.R., G.B. and S.A.; visualization, T.R.; project administration, T.R. and A.R.; funding acquisition, T.R., A.R. and T.K.; Formal analysis, G.B. All authors have read and agreed to the published version of the manuscript.

Funding: This research received no external funding.

Institutional Review Board Statement: Not applicable.

Informed Consent Statement: Informed consent was obtained from all subjects involved in the study.

Data Availability Statement: Data is available from the first author.

Conflicts of Interest: The authors are not aware of any conflict of interest.

\section{References}

1. Neale, M.J. (Ed.) Tribology Handbook, 2nd ed.; Butterworth-Heinemenn Elsevier Ltd.: Oxford, UK, 1996; ISBN 978-0-7506-1198-5. [CrossRef]

2. Peter, R.N. Childs Pneumatics and hydraulics. In Mechanical Design Engineering Handbook; Butterworth-Heinemenn, Elsevier Ltd.: Oxford, UK, 2019; pp. 849-874. [CrossRef]

3. Adams, J.P.; Alven, D.A.; Amaya, H.E.; Apelian, D.; Assel, M.; Banik, M.; Baumeister, J.; Beiss, P.; Bose, A.; Bratland, P.; et al. Powder Metallurgy: The Materials International Society; ASM Handbook: New York, NY, USA, 2015 ; Volume 7, p. 907. ISBN 978-1-62708-089-3.

4. Migranov, M.S.; Mukhamadeev, V.R.; Migranov, A.M.; Mukhamadeev, I.R.; Khazgalieva, A.A. The improvement of the tribotechnical properties of materials and coatings for metal cutting tool. IOP Conf. Ser. Mater. Sci. Eng. 2018, 447, 012083.

5. Roik, T.; Gavrish, O.; Oliynik, V.; Vitsiuk, I. Analysis of the properties of antifriction composites based on aluminum alloy's grinding waste. East. Eur. J. Enterp. Technol. 2018, 4, 16-22. [CrossRef]

6. Jamroziak, K.; Roik, T. New Antifriction Composite Materials Based On Tool Steel; Press Ashurst Lodge, Ashurst: Southampton, UK; Computational Mechanics International Inc.: Billerica, MA, USA, 2021; Volume 124, pp. 151-159. ISBN 978-1-78466-331-5. [CrossRef] 
7. Roik, T.; Gavrysh, O.; Vitsiuk, I. Tribotechnical Properties of Composite Materials Produced from ShKh15SG Steel Grinding Waste. In Powder Metallurgy and Metal Ceramics; Springer Science + Business Media, LLC: New York, NY, USA, 2019; Volume 58, pp. 439-445. Available online: http:/ /link.springer.com/article/10.1007/s11106-019-00093-w (accessed on 5 December 2020). [CrossRef]

8. Verhoeven, J.D. Steel Metallurgy for the Non-Metallurgist; ASM International: Novelty, OH, USA, 2007; p. 159. Available online: https://www.researchgate.net/publication/268324669_Steel_Metallurgy_for_the_Non-Metallurgist (accessed on 9 November 2014).

9. Oberg, E.; Jones, F.D.; McCauley Christopher, J.; Hill Ricardo, M. Handbook of Machinery, 27th ed.; Industrial Press: New York, NY, USA, 2004; ISBN 978-0-8311-2700-8.

10. Boccalini, M.; Goldenstein, H. Solidification of high speed steels. Int. Mater. Rev. 2001, 46, 92-115. [CrossRef]

11. Bayer, A.M.; Becherer, B.; Vasco, T. High Speed Tool Steels; Machining; ASM International: Novelty, OH, USA, 1989; Volume 16, 59p, ISBN 978-0-87170-022-3. Available online: www.asminternational.org (accessed on 5 December 2020).

12. Roik, T.A.; Gavrish, A.P.; Kirichok, P.A.; Vitsyuk, Y.Y. Effect of Secondary Structures on the Functional Properties of HighSpeed Sintered Bearings for Printing Machines. Powder Met. Met. Ceram. 2015, 54, 119-127. [CrossRef]

13. Jamroziak, K.; Roik, T.; Gavrish, O.; Vitsiuk, I.; Lesiuk, G.; Correia, J.A.; De Jesus, A.M. Improved manufacturing performance of a new antifriction composite parts based on copper. Eng. Fail. Anal. 2018, 91, 225-233. [CrossRef]

14. Jamroziak, K.; Roik, T. Structure and Properties of the New Antifriction Composite Materials for High-Temperature Friction Units. In Proceedings of the 2nd Annual International Conference on Material, Machines and Methods for Sustainable Development (MMMS2020), Nha Trang, Vietnam, 12-15 November 2020; Springer Science and Business Media LLC: Berlin, Germany, 2021; pp. 628-637. Available online: https:/ /www.springer.com/gp/book/9783030696092 (accessed on 5 December 2020).

15. Kurzawa, A.; Roik, T.; Gavrysh, O.; Vitsiuk, I.; Bocian, M.; Pyka, D.; Zajac, P.; Jamroziak, K. Friction mechanism features of the nickel-based composite antifriction materials at high temperatures. Coatings 2020, 10, 454. [CrossRef]

16. Jamroziak, K.; Roik, T. Friction Films and Their Influence on the Antifriction Properties of New High-Temperature Nickel Composites. In Proceedings of the 8th International Conference on Fracture Fatigue and Wear FFW-2020; Springer: Berlin/Heidelberg, Germany, 2020; ISBN 978-981-15-9893-7. [CrossRef]

17. Jianxin, D.; Tongkun, C. Self-lubricant mechanisms via the in situ formed tribofilm of sintered ceramics with $\mathrm{CaF}_{2}$ additions when sliding against hardened steel. Int. J. Refract. Met. Hard Mater. 2007, 25, 189-197.

18. Material and Powder Properties; Höganäs Handbook for Sintered Components; Höganäs AB laboratory: Höganäs, Sweden, December 2013; 113p, Available online: www.hoganas.com/pmc (accessed on 5 December 2020).

19. Kruzhanov, V. Modern Manufacturing of Powder-Metallurgical Products with High Density and Performance by Press-Sinter Technology. Powder Met. Met. Ceram. 2018, 57, 431-446. [CrossRef]

20. Oro, R.; Campos, M.; Gierl-Mayer, C.; Danninger, H.; Torralba, J.M. New Alloying Systems for Sintered Steels: Critical Aspects of Sintering Behavior. Met. Mater. Trans. A 2014, 46, 1349-1359. [CrossRef]

21. Duxbury, P.M.; Rzepniewski, E.; Moukarzel, C. Structure-Sensitive Properties of Materials. In Proceedings of the IUTAM Symposium on Nonlinear Analysis of Fracture, Cambridge, UK, 3-7 September 1995; Solid Mechanics and Its Applications; Willis, J.R., Ed.; Springer Science + Business Media: Dordrecht, The Netherlands, 1997; Volume 49, pp. 257-264. [CrossRef]

22. Rashedi, A.; Sridhar, I.; Tseng, K. Fracture characterization of glass fiber composite laminate under experimental biaxial loading. Compos. Struct. 2016, 138, 17-29. [CrossRef]

23. Ali, A.; Ali, F.; Rashedi, A.; Armghan, A.; Fajita, M.R.; Alenezi, F.; Babu, N.B. Fabrication and Characterization of Physical and Mechanical Properties of Carbon Nanotubes-Graphene-Based Sandwich Composite Pressure Sensor. Nanomaterials 2021, 11, 1284. [CrossRef]

24. Rashedi, A.; Sridhar, I.; Tseng, K.; Idapalapati, S. Life cycle assessment of 50MW wind firms and strategies for impact reduction. Renew. Sustain. Energy Rev. 2013, 21, 89-101. [CrossRef]

25. Rashedi, A.; Khanam, T. Life cycle assessment of most widely adopted solar photovoltaic energy technologies by mid-point and end-point indicators of ReCiPe method. Environ. Sci. Pollut. Res. 2020, 27, 29075-29090. [CrossRef] 